\title{
$\mathrm{N}$-스크린서비스 환경에서 웹콘텐츠 이동/결합/분리를 고려한 보안 기술 분석 및 협업 서비스 프레임워크 개발
}

이호원*

\section{Research on Technical Requirements of Security for Migration, Combination, and Separation of Web-Contents and Development of Cooperation Service Framework in N-Screen Services}

\author{
Howon Lee* \\ Department of Electrical, Electronic and Control Engineering \& IITC, Hankyong National University, \\ Anseong 456-749, Korea

\section{요 약} \\ 스마트 디바이스의 수가 급증함에 따라 다양한 스크린들 간의 협업을 통하여 사용자들에게 새로운 사용자 경험 \\ (User Experience)을 제공할 수 있는 N-스크린서비스에 대한 수요가 급증하고 있으며, 이는 사용자들에게 기술적 풍 \\ 요를 제공하는 동시에 새로운 보안상의 약점을 유발하게 되었다. 본 논문은 기존의 다양한 웹 공격유형에 대하여 분 \\ 석하고, 미래 N-스크린서비스 시나리오들을 기반으로 웹콘텐츠의 이동/결합/분리를 위한 새로운 보안 요구사항을 \\ 제안하고 이를 구체적으로 정리하고 분석해 본다. 또한, $\mathrm{N}$ 스크린 환경에서 웹콘텐츠의 이동을 통하여 사용자의 개 \\ 인 정보가 공공 디바이스를 통해 외부로 공개되는 것을 방지할 수 있는 방안이 적용된 N스크린 협업서비스 프레임워 \\ 크에 대해서 살펴본다.
}

\section{ABSTRACT}

According to explosion of smart-devices, demands on $\mathrm{N}$-screen services based on cooperation of multiple screens are rapidly increasing. These $\mathrm{N}$-screen services can provide new user-experience (UX) to users. That is, it can provide technical advances to users. On the other hand, it causes new security problems. In this paper, we analyze conventional web-security attacks, and we propose and analyze new security requirements for migration, combination, and separation of web-contents based on $\mathrm{N}$-screen service scenarios. Also, we develop N-screen cooperation service framework in order to ensure user security.

키워드 : N-스크린서비스, 웹콘텐츠, 보안 기술, 서비스 프레임워크

Key Words : N-Screen Service, Web Content, Security Requirement, Service Framework 


\section{I. 서 론}

최근 스마트 디바이스의 수가 급증함에 따라 사용자 들은 자신이 보유한 콘텐츠를 여러 디바이스를 통해서 동시에 끊김없이 재생하거나 디바이스-협력적 콘텐츠 재생을 통한 사용자 경험(User Experience)의 극대화를 위한 요구가 늘어나고 있다. 일반적으로 $\mathrm{N}$-스크린서 비스란 개인이 가지고 있거나 혹은 개인 주변에 있는 다양한 스크린들(스마트 TV, 스마트폰, 데스크톱 PC, 스마트패드, 게임기 등)을 통해 콘텐츠를 끊김없고 (seamless) 실감나게(real) 재생할 수 있는 서비스를 말 한다[1-3].

예를 들면, 옥외에서 자신의 스마트패드로 보고 있던 동영상이 실내로 이동할 경우 거실의 스마트 TV와 홈 오디오 시스템을 통해 재생되고 있던 시간 이후부터 연 속적으로 재생되는 서비스를 의미한다. $\mathrm{N}$-스크린서비 스는 다양한 스크린들 간의 협업을 통해 사용자들에게 새로운 사용자 경험을 제공하며, 사용자들에게 끊김없 는 서비스를 제공하는 동시에 시간과 공간의 제약을 넘 어서 자유로운 콘텐츠 공유 및 이용을 가능하게 한다 [4-5]. N-스크린서비스는 스마트교육, 스마트워크, 디지 털 사이니지, 스마트의료 등 다양한 IT융합 산업에 활 용될 수 있는 핵심 서비스 기술이다.

새로운 기술의 등장으로 인한 체계의 변화는 필연적 으로 이에 따른 새로운 보안상의 약점 노출을 유발하게 된다. 특히, 다양한 접속방식 및 범용성을 가지는 웹 기 술의 경우 이러한 약점을 노출할 가능성이 높은 편이다. 안정적인 웹서비스를 위해서는 사용자의 서비스 이용 에 대한 기밀성(Confidentiality), 무결성(Integrity), 그 리고 가용성(Availability)이 보장되어야만 한다[6]. 따 라서 새로운 웹 기반 서비스를 제공하기에 앞서, 서비 스의 기능성 및 보안성, 그리고 기술 개발 시 고려해야 할 사항에 대한 철저한 분석이 필요하다[7-8].

본 논문의 II장에서는 기존의 웹 기반 공격방식에 대 해서 조사하고, III장에서는 이동형 웹 콤포넌트를 고려 한 보안 대비방안에 대하여 알아보도록 한다. IV장에서 는 N-스크린서비스 시나리오들에 대한 각각의 보안 요 구사항에 대하여 분석하고 제안하며, V장에서는 보안 기술이 적용된 $\mathrm{N}$ 스크린 협업서비스 프레임워크에 대해 알아본다. VI장에서 본 논문을 마무리한다.

\section{ㅍ. 기존연구조사: 웹기반 공격방식조사}

본 장에서는 다양한 웹기반 공격방식에 대해 살펴보 고 각각을 위한 대비방법에 대하여도 간략히 알아보도 록 한다[9-10].

1) Cross-Site Scripting (XSS): 클라이언트 측 공격으 로, 동적 페이지에 스크립트를 삽입하여 공격하는 방법 이다. 요즘의 웹 사이트들은 Flash, IMG 등의 동적인 페 이지를 제공하므로 XSS에 취약하다. XSS는 바이러스 로 변하면 심각한 문제를 일으킬 수 있다.

2) Redirection Attacks: 사용자의 브라우저로 하여금 요청된 URL (Uniform Resource Locator)과 다른 URL 로 방문하도록 지시하는 것을 redirection이라고 한다. Redirection 공격의 취약성은 어플리케이션이 사용자가 조작 가능한 입력을 취하고, 이를 redirection 수행에 사 용할 때 발생한다.

3) HTTP Header Injection: HTTP의 헤더에 데이터를 삽입하는 방법이다. HTTP Header Injection의 취약성은 사용자가 직접 조작 가능한 데이터가 어플리케이션에 의해 반환되는 HTTP 헤더에 불안전한 방법으로 삽입될 때 발생한다. Location과 Set-Cookie 헤더에서 흔히 취약 성이 발견된다.

4) Frame Injection: Frame Injection이란 말 그대로 프레임에 어떤 데이터나 내용을 쓰는 것이다. Frame injection의 취약성은 주로 웹 사이트가 이름 속성을 가 진 프레임을 생성할 때 발견된다. 프레임에는 이름 속 성이 있으며, 이를 익명 혹은 특정한 이름으로 설정할 수 있다.

5) Cross-Site Request Forgery (XSRF): XSRF란 사 용자가 자신의 의지와는 무관하게, 공격자가 의도한 행 위(수정, 삭제 등)를 특정 웹사이트에 요청하게 되는 공 격 방식이다. 공격자가 작성해 놓은 악성 코드를 통해 일어나는 공격이며, stored XSS와 유사하다. 하지만, $\mathrm{XSRF}$ 는 인증 완료된 사용자의 권한으로 악성 스크립 트를 서버에 요청한다는 면에서 XSS와는 다르다.

6) JSON Hijacking: JSON은 임의의 데이터를 직렬 화하고, JavaScript interpreter에 의해 직접 실행될 수 있 는 간단한 데이터 전송 포맷이다. JSON hijacking은 XSRF 공격의 특별한 버전이다.

7) Session Fixation: 웹 세션 보안은 공격자가 웹 서 버에서 발행된 세션 $\mathrm{ID}$ 를 얻지 못하게 하는데 주로 초 
점이 맞춰져 있다. 사용자가 로그인 시, 세션 ID가 임의 적으로 만들어지는 것 대신에 공격자가 사용자의 세션 $\mathrm{ID}$ 를 설정하게 된다.

8) Attacking ActiveX Controls: ActiveX는 기술적 제 약이 적어서 자신도 모르는 사이 악성 소프트웨어가 유 입될 수 있고, 호환성 문제도 있어서 최근 선호도가 줄 고 있다.

\section{III. 이동형 웹콤포넌트 보안 방안}

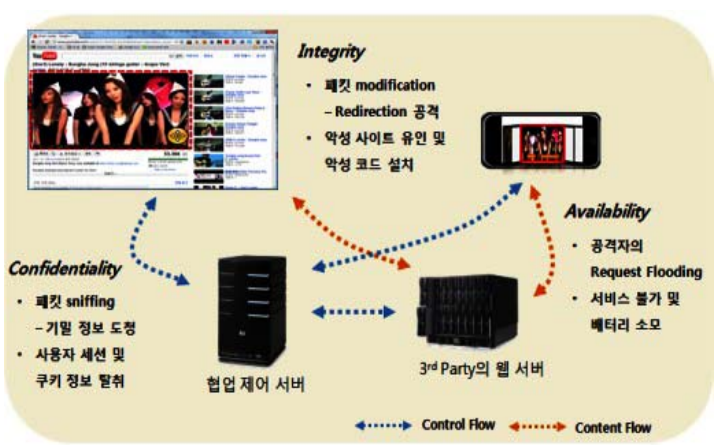

그림 1. 웹 콤포넌트에서의 보안 유의사항 3요소

Fig. 13 Primary Elements of Web Security

이동형 웹 컴포넌트 기술은 웹 융합 콘텐츠를 $\mathrm{N}$ 스크 린 환경에서 활용함으로 그 사용성을 극대화 할 수 있 는 기술이며, 사용자는 본 기술을 바탕으로, 웹 환경에 끊김없는 접근이 가능하다. 그림 1 은 $\mathrm{N}$ 스크린 환경에 서 이동형 웹 서비스가 안정적으로 운영되기 위해 보장 해야 할 기본적인 보안 요구사항 3요소에 대해서 나타 내고 있다.

- 기밀성 (Confidentiality): 본 서비스의 제공에 있어 서, 사용자의 단말 내 존재하거나 네트워크를 통해 전달되는 사용자의 데이터는 데이터의 특성에 따라 다른 시스템에 노출되지 않아야 한다.

- 무결성 (Integrity): 사용자의 끊김없는 웹 연결을 위 해서는, 단말 간에 접속정보에 대한 이동이 필요하 다. 이 때, 이동 되는 데이터는 다른 시스템에 의해 변경되지 않아야 한다.

- 가용성 (Availability): 단말간의 서비스 이동을 위해 서는, 단말 사이의 컨트롤 정보의 이동이 필수적이
다. 본 컨트롤 정보는 단말 간의 동기화 혹은 연속적 정보 전달을 위한 신호로 사용된다. 본 서비스를 이 용하는 사용자는 다른 시스템의 방해 없이, 원하는 장소, 시간에 서비스를 사용 받을 수 있어야 한다.

\section{N-스크린 협업서비스 시나리오 기반 보안 요구사항 제안 및 분석}

본 장에서는 $\mathrm{N}$-스크린 환경에서 발생할 수 있는 다 양한 협업서비스 시나리오들을 분석하고 이를 위한 보 안 요구사항들을 제안하고 분석한다. 각각의 시나리오 에서 발생할 수 있는 취약성을 분석함으로써, 웹 및 네 트워크 공격에 대해 안정적인 서비스를 제공하는 것이 본 IV장의 중요 목표이다.

\subsection{K-pop 시나리오}

4.1.1. 시나리오 설명

(a) 이동 웹 컴포넌트 기술이 반영된 스마트 TV에서 친 구와 함께 소녀시대의 뮤직 비디오 감상, 스크린 하 단에 소녀 시대에 대한 한 줄 기사를 보고, 사용자는 뮤직 비디오 화면에 방해를 받지 않는 환경에서 기 사를 보고 싶어 한다.

(b) 본 기사를 사용자의 휴대 단말에서 확인하기 위해, $\mathrm{TV}$ 에서 사용자 휴대 단말을 선택하고, 해당 단말에 서 서비스 요청을 확인한다.

(c) 사용자 휴대 단말에서 TV에서 노출된 해당 기사를 받아서 읽는다.

(d) 사용자는 소녀시대의 음악이 마음에 들어, 구매를 요청하였고, 본 구매 프로세스는 사용자의 휴대 단 말로 이동되어 진행되었다.

\subsection{2. 보안 요구사항}

표 1. K-Pop 시나리오 보안 요구사항

Table. 1 Service Requirement of K-Pop Scenario

\begin{tabular}{|c|l|l|l|}
\hline ID & \multicolumn{1}{|c|}{ 요구사항 } & \multicolumn{1}{|c|}{ 공격 유형 } & 대응방안 \\
\hline \hline \multirow{4}{*}{ SEC- } & 이동 컨텐츠는 허 & ARP & \\
1.001 & 용된 인증된 사용 & Spoofing, Switch & 인증 및 \\
& 자만 접근할 수 있 & jamming등을 이 & 암호화 \\
& 어야 한다. & 용한 도청 & \\
\hline
\end{tabular}




\begin{tabular}{|l|l|l|c|}
\hline SEC- & $\begin{array}{l}\text { 구매 프로세스 시, } \\
\text { 전달되는 구매자 } \\
\text { 의 정보는 노출되 } \\
\text { 지 않아야 한다. }\end{array}$ & $\begin{array}{l}\text { ARP } \\
\text { Spoofing, Switch } \\
\text { jamming등을 이 } \\
\text { 용한 도청 }\end{array}$ & $\begin{array}{c}\text { 접근 통제 } \\
\text { 암호화 }\end{array}$ \\
\hline SEC- & $\begin{array}{l}\text { 구매 프로세스 시, } \\
\text { 휴대 단말은 안전 } \\
1.003\end{array}$ & $\begin{array}{l}\text { Redirection 공격, } \\
\text { 한 사이트로 연결 } \\
\text { 되어야 한다. }\end{array}$ & $\begin{array}{l}\text { 등을 이용한 피싱 } \\
\text { 해시 기반 } \\
\text { 전자 서명 }\end{array}$ \\
\hline SEC- & $\begin{array}{l}\text { 휴대 단말에 연결 } \\
\text { 요청은 상호 인증 } \\
1.004\end{array}$ & $\begin{array}{l}\text { Service Request 사용자의 접속 } \\
\text { 만을 허용한다. }\end{array}$ & $\begin{array}{c}\text { 비정상 } \\
\text { Request } \\
\text { 탐지, } \\
\text { 인증 }\end{array}$ \\
\hline
\end{tabular}

\section{2. 공공 디스플레이 광고 시나리오}

4.2.1. 시나리오 설명

(a) 카페 광고를 위해, 사용자는 이미지 저작 웹 어플리 케이션을 통해 광고 포스터를 제작하고, 본인의 휴 대 단말기에 입력한다.

(b) 사용자는 공공 디스플레이 앞에 도착한 후, 휴대 단 말을 통해 웹 응용을 실행시킨다.

(c) 사용자는 이동형 웹 컴포넌트 기술을 기반으로 광고 디스플레이와 본인의 휴대 단말에 있는 웹 응용의 디스플레이를 연계시킨다. 광고 디스플레이의 터치 스크린을 통해 본인이 원하는 광고 영역만큼을 확대 및 축소시킨다.

4.2.2. 보안 요구사항

표 2. 공공 디스플레이 광고 시나리오 보안 요구사항 Table. 2 Service Requirement of Public Display Advertisement Scenario

\begin{tabular}{|c|c|c|c|}
\hline ID & 요구사항 & 공격 유형 & 대응방안 \\
\hline $\begin{array}{l}\text { SEC- } \\
2.001\end{array}$ & $\begin{array}{l}\text { 광고주의 아이디 } \\
\text { 도용을 막아, 불법 } \\
\text { 과금 체계를 방지 } \\
\text { 한다. }\end{array}$ & $\begin{array}{l}\text { 도청 공격 및 } \\
\text { XSS 공격 }\end{array}$ & $\begin{array}{c}\text { 안전한 } \\
\text { 사용자 인증 } \\
\text { 및 사이트 } \\
\text { 설계 }\end{array}$ \\
\hline $\begin{array}{l}\text { SEC- } \\
2.002\end{array}$ & $\begin{array}{l}\text { 광고 플랫폼 관리 } \\
\text { 서버는 사용자 정 } \\
\text { 보를 안전하게 보 } \\
\text { 관해야 한다. }\end{array}$ & $\begin{array}{l}\text { 관리 서버에 } \\
\text { 대한 SQL } \\
\text { injection, } \\
\text { 파라미터 변조 } \\
\text { 등을 통한 해킹 }\end{array}$ & $\begin{array}{c}\text { 분산 웹서버 } \\
\text { 시스템, } \\
\text { 특수문자 } \\
\text { 방지, 안전한 } \\
\text { 사이트 설계 }\end{array}$ \\
\hline $\begin{array}{l}\text { SEC- } \\
2.003\end{array}$ & $\begin{array}{l}\text { 사용자의 광고 영 } \\
\text { 역은 사업자와의 } \\
\text { 계약기간 동안 안 } \\
\text { 전하게 보존되어 } \\
\text { 야 한다. }\end{array}$ & $\begin{array}{l}\text { 관리 서버에 } \\
\text { 대한 SQL } \\
\text { injection, } \\
\text { 파라미터 변조 } \\
\text { 등을 통한 해킹 }\end{array}$ & $\begin{array}{c}\text { 안전한 } \\
\text { 사이트 설계, } \\
\text { 웹서버 권한 } \\
\text { 관리 }\end{array}$ \\
\hline
\end{tabular}

\begin{tabular}{|l|l|l|c|}
\hline \multirow{4}{*}{ SEC- } & $\begin{array}{c}\text { 사용자의 광고 디 } \\
\text { 스플레이 파일은 }\end{array}$ & ARP Spoofing, & \\
Rogued AP, & 다른 시스템에 의 & MITM (Man In & 암호화 및 \\
& 해 노출되거나 변 & The Middle) & 디털 서명, \\
& 조되어서는 안 된 & attack 등의 & AP인증 \\
& 다. & 도청 및 변조 & \\
\hline
\end{tabular}

\section{3. 오피스 미팅 시나리오}

4.3.1. 시나리오 설명

(a) 팀장 $\mathrm{A}$ 와 팀원 $\mathrm{B}, \mathrm{C}, \mathrm{D}$ 는 신제품 개발을 위한 브레 인스토밍을 하기 위해 A, B, C는 한 자리에 모였으 며, $\mathrm{D}$ 는 온라인으로 회의하기로 하였다.

(b) 팀장과 각 팀원들은 협업 캔버스 기능이 가능한 공 용 스마트 스크린에 각자의 스마트폰의 브라우저를 통해 접속하였다.

(c) 각 팀원들은 각자 단말을 이용하여 필요한 자료를 검색하였고, 팀장은 협업 캔버스를 통해 이를 모니 터 하고, 공용 공간에 중요한 자료들을 뽑아 작업하 였다.

\subsection{2. 보안 요구사항}

표 3. 오피스미팅 시나리오 보안 요구사항

Table. 3 Service Requirement of Office Meeting Scenario

\begin{tabular}{|c|c|c|c|}
\hline ID & 요구사항 & 공격 유형 & 대응방안 \\
\hline $\begin{array}{l}\text { SEC- } \\
3.001\end{array}$ & $\begin{array}{l}\text { 오피스 미팅을 지원 } \\
\text { 하는 웹 사이트는 사 } \\
\text { 용자의 개인 정보를 } \\
\text { 보호해야한다. }\end{array}$ & $\begin{array}{l}\text { SQL injection } \\
\text { 등의 해킹과 } \\
\text { 내부자 공격 }\end{array}$ & $\begin{array}{l}\text { 안전한 } \\
\text { 사이트 설계, } \\
\text { 접근 권한 } \\
\text { 관리 }\end{array}$ \\
\hline $\begin{array}{l}\text { SEC- } \\
3.002\end{array}$ & $\begin{array}{l}\text { 웹에서 사용자 간 서 } \\
\text { 로 주고 받는 자료는 } \\
\text { 외부에 노출되지 않 } \\
\text { 아야 한다. }\end{array}$ & $\begin{array}{l}\text { ARP Spoofing, } \\
\text { Rogued AP, } \\
\text { MITM Attack } \\
\text { 등의 도청 및 } \\
\text { 변조 }\end{array}$ & $\begin{array}{c}\text { 데이터 } \\
\text { 암호화 및 } \\
\text { 인증 }\end{array}$ \\
\hline $\begin{array}{l}\text { SEC- } \\
3.003\end{array}$ & $\begin{array}{l}\text { 협업 캔버스에는 각 } \\
\text { 사용자가 허용하는 } \\
\text { 정보만이 노출되어 } \\
\text { 야 한다. 또한 주고 } \\
\text { 받는 자료 안에 악성 } \\
\text { 코드가 포함되어있 } \\
\text { 으면 안 된다. }\end{array}$ & $\begin{array}{l}\text { 시스템 해킹, } \\
\text { 악성코드 }\end{array}$ & $\begin{array}{l}\text { 접근 권한 } \\
\text { 관리, } \\
\text { 침입탐지 } \\
\text { 시스템 }\end{array}$ \\
\hline $\begin{array}{l}\text { SEC- } \\
3.004\end{array}$ & $\begin{array}{l}\text { 회의가 끝난 후, 협 } \\
\text { 업 캔버스에는각 사 } \\
\text { 용자의 쿠키 정보 등 } \\
\text { 이 삭제되어야 한다. }\end{array}$ & 개인정보 탈취 & 보안 코딩 \\
\hline
\end{tabular}




\section{4. 이동식 동영상 재생 시나리오}

4.4.1. 시나리오 설명

(a) 학교 컴퓨터에서 인터넷으로 동영상을 감상하던 사 용자는 집으로 돌아가려한다. 현재 컴퓨터에서 보던 동영상을 자신의 휴대 단말기에서 끊김없이 감상한 다.

(b) 집에 돌아온 사용자는 휴대단말의 작은 화면에 불만 을 느껴 집 안의 스마트 TV에 동영상을 옮기고, 자 신의 휴대단말로 텍스트를 출력하고 TV 화면을 컨 트롤한다.

\subsection{2. 보안 요구사항}

표 4. 이동식 동영상 재생 시나리오 보안 요구사항 Table. 4 Service Requirement of Video Scenario

\begin{tabular}{|c|c|c|c|}
\hline ID & 요구사항 & 공격 유형 & 대응방안 \\
\hline $\begin{array}{l}\text { SEC- } \\
4.001\end{array}$ & $\begin{array}{l}\text { 각 디바이스간의 호 } \\
\text { 출은 다른 시스템에 } \\
\text { 의해서 접근되거나 } \\
\text { 방해받지 않아야한 } \\
\text { 다. }\end{array}$ & $\begin{array}{l}\text { IP Spoofing, } \\
\text { Request } \\
\text { Flooding }\end{array}$ & $\begin{array}{c}\text { 상호 } \\
\text { 인증을 } \\
\text { 통한 접근 } \\
\text { 관리 }\end{array}$ \\
\hline $\begin{array}{l}\text { SEC- } \\
4.002\end{array}$ & $\begin{array}{l}\text { 컨트롤 정보에 포함 } \\
\text { 된 세션 유지 정보는 } \\
\text { 외부로 노출되지 않 } \\
\text { 아야한다. }\end{array}$ & $\begin{array}{l}\text { ARP Spoofing, } \\
\text { Rogued AP } \\
\text { 등의 도청 공격, } \\
\text { Session } \\
\text { Hijacking }\end{array}$ & $\begin{array}{l}\text { 암호화 및 } \\
\text { 정교한 } \\
\text { 사용자 } \\
\text { 인증기법 }\end{array}$ \\
\hline $\begin{array}{l}\text { SEC- } \\
4.003\end{array}$ & $\begin{array}{l}\text { 컨트롤 정보에 포함 } \\
\text { 된 세션 정보는 변 } \\
\text { 조, 조작 되어서는 } \\
\text { 안된다. }\end{array}$ & $\begin{array}{l}\text { Frame Injection, } \\
\text { Redirection, } \\
\text { 사회공학적 } \\
\text { 피싱 }\end{array}$ & $\begin{array}{c}\text { 해쉬기반 } \\
\text { 의 무결성 } \\
\text { 보장 및 } \\
\text { 암호화 }\end{array}$ \\
\hline $\begin{array}{l}\text { SEC- } \\
4.004\end{array}$ & $\begin{array}{l}\text { 재생이 끝난 후, 공 } \\
\text { 용 TV에서는 각 사 } \\
\text { 용자의 쿠키 정보 등 } \\
\text { 이 삭제되어야 한다. }\end{array}$ & 개인정보 탈취 & 보안 코딩 \\
\hline
\end{tabular}

\section{5. 피겨스케이팅 시나리오}

4.5.1. 시나리오 설명

(a) 사용자 $\mathrm{A}$ 는 피겨 스케이팅을 친구와 함께 감상 중 인데, 한 친구 B가 TV의 화면 분할을 이용하여 검색 을 수행한다. 사용자 $\mathrm{A}$ 는 친구 $\mathrm{B}$ 에게 스케이팅 보 는데 방해된다며, $\mathrm{B}$ 의 개인단말에서 검색해줄 것을 요청한다.

(b) 친구 $\mathrm{B}$ 는 공용 $\mathrm{TV}$ 에서 검색하던 검색 브라우저의 상태를 개인 휴대 단말에 바로 가져와 연속적인 검 색을 수행한다. (c) 친구 $\mathrm{B}$ 는 검색 중, 아사다마오의 트리플 악셀에 관 한 자료를 발견했으며, 사용자 A도 검색 결과에 대 해 궁금해 한다.

(d) 친구 $\mathrm{B}$ 는 공용 $\mathrm{TV}$ 에 본인의 검색 결과를 화면에 띄 워 $\mathrm{A}$ 와 함께 그 검색 결과를 공유한다.

\subsection{2. 보안 요구사항}

표 5. 피겨스케이팅 시나리오 보안 요구사항

Table. 5 Service Requirement of Figure-Skating Scenario

\begin{tabular}{|c|c|c|c|}
\hline ID & 요구사항 & 공격 유형 & 대응방안 \\
\hline $\begin{array}{l}\text { SEC- } \\
5.001\end{array}$ & $\begin{array}{l}\text { 공용 TV에서는 허용 } \\
\text { 된 사용자만이 접근 } \\
\text { 및 조정 가능해야만 } \\
\text { 한다. }\end{array}$ & 권한 위반 & 보안 코딩 \\
\hline $\begin{array}{l}\text { SEC- } \\
5.002\end{array}$ & $\begin{array}{l}\mathrm{TV} \text { 에서 휴대 단말로 } \\
\text { 브라우징 상태가 외 } \\
\text { 부에 노출 없이 전달 } \\
\text { 되어야한다. }\end{array}$ & $\begin{array}{l}\text { 무선 도청, } \\
\text { ARP Spoofing } \\
\text { 등 }\end{array}$ & $\begin{array}{l}\text { 암호화 통신 } \\
\text { 및 사용자 } \\
\text { 인증 }\end{array}$ \\
\hline $\begin{array}{l}\text { SEC- } \\
5.003\end{array}$ & $\begin{array}{l}\text { 각 사용자 단말 간에 } \\
\text { 받는 자료안에 악성 } \\
\text { 코드가 포함되어있 } \\
\text { 으면 안 된다. }\end{array}$ & 악성코드 전파 & $\begin{array}{l}\text { 침입탐지 } \\
\text { 시스템 }\end{array}$ \\
\hline
\end{tabular}

\section{6. 보안기술 요구사항 정리 및 분석}

표 6은 각각의 시나리오들의 요구사항을 보안 유의 사항의 요소별로 정리하는 동시에 각각의 요구사항의 특징들을 뽑아 정형화된 요구사항으로 정리한 것이다.

표 6. 보안 요구사항 정리

Table. 6 Summary of Service Requirements

\begin{tabular}{|c|c|c|c|}
\hline No. & 요구사항 & ID & 유형 \\
\hline 1 & $\begin{array}{l}\text { 서비스 사용을 위해 전달되는 } \\
\text { 사용자 개인 정보(사용자 ID, 구 } \\
\text { 매정보, 사용자 위치, 서비스 종 } \\
\text { 류 등)는 외부로부터 보호받아 } \\
\text { 야 한다. }\end{array}$ & $\begin{array}{l}\text { SEC-1.001 } \\
\text { SEC-1.002 } \\
\text { SEC-2.004 } \\
\text { SEC-3.002 } \\
\text { SEC-4.002 } \\
\text { SEC-5.002 }\end{array}$ & 기밀성 \\
\hline 2 & $\begin{array}{l}\text { 각 단말간에 주고 받는 정보들 } \\
\text { 은 외부로부터 변조되지 않고 } \\
\text { 그대로 전송 되어야 한다. }\end{array}$ & $\begin{array}{l}\text { SEC-1.003 } \\
\text { SEC-2.004 } \\
\text { SEC-4.003 }\end{array}$ & 무결성 \\
\hline 3 & $\begin{array}{l}\text { 사용자 단말 간에 주고 받는 정 } \\
\text { 보를 통해 악성 코드 등이 전파 } \\
\text { 되지 않아야 한다. }\end{array}$ & SEC-3.003 & 무결성 \\
\hline
\end{tabular}




\begin{tabular}{|c|c|c|c|}
\hline 4 & $\begin{array}{l}\text { 공공의 목적으로 사용되는 협업 } \\
\text { 스크린은 이를 이용하는 사용자 } \\
\text { 의 개인 정보가 노출되지 않도 } \\
\text { 록 해킹 등으로부터 안전해야 } \\
\text { 한다. }\end{array}$ & $\begin{array}{l}\text { SEC-3.003 } \\
\text { SEC-3.004 } \\
\text { SEC-4.004 }\end{array}$ & 기밀성 \\
\hline 5. & $\begin{array}{l}\text { 사용자의 단말들간의 연계를 담 } \\
\text { 당하는 제어서버는 외부 침입으 } \\
\text { 로부터 안전하게 설계되어야 하 } \\
\text { 며, 서버 내의 사용자 } \mathrm{DB} \text { 는 강 } \\
\text { 력히 암호화 되어야 한다. }\end{array}$ & $\begin{array}{l}\text { SEC-2.002 } \\
\text { SEC-3.001 } \\
\text { SEC-4.002 }\end{array}$ & 기밀성 \\
\hline 6 & $\begin{array}{l}\text { 사용자의 단말간의 연계를 담당 } \\
\text { 하는 제어서버는 저장된 자료의 } \\
\text { 손실을 막기 위한 백업 기능을 } \\
\text { 제공해야한다. }\end{array}$ & $\begin{array}{l}\text { SEC-2.005 } \\
\text { SEC-3.005 }\end{array}$ & $\begin{array}{l}\text { 기밀성 } \\
\text { 가용성 }\end{array}$ \\
\hline 7 & $\begin{array}{l}\text { 사용자의 단말에 대한 서비스 } \\
\text { 요청은 인증 및 허용된 단말기 } \\
\text { 만이 가능하도록 하여, 불필요 } \\
\text { 한 서비스 요청으로 인한 사용 } \\
\text { 자의 불편을 최소화하여야한다. }\end{array}$ & $\begin{array}{l}\text { SEC-1.004 } \\
\text { SEC-4.001 } \\
\text { SEC-5.001 }\end{array}$ & 가용성 \\
\hline 8 & $\begin{array}{l}\text { 각 사용자의 권한에 대한 적절 } \\
\text { 한 통제를 하여, 사용자의 권한 } \\
\text { 남용을 막는다. }\end{array}$ & $\begin{array}{l}\text { SEC-2.003 } \\
\text { SEC-5.001 }\end{array}$ & 기밀성 \\
\hline 9 & $\begin{array}{l}\text { 아이디의 도용을 막아, 서비스 } \\
\text { 를 이용하는 고객에 대한 불법 } \\
\text { 과금을 막아야한다. }\end{array}$ & $\begin{array}{l}\text { SEC-1.005 } \\
\text { SEC-2.001 }\end{array}$ & $\begin{array}{l}\text { 사용자 } \\
\text { 인증 } \\
\text { (기타) }\end{array}$ \\
\hline
\end{tabular}

그림 2로부터 우리는 $\mathrm{N}$ 스크린 환경에서 공격 유형의 발생빈도를 살펴 볼 수 있다. $\mathrm{N}$ 스크린 환경에서 웹콘테 츠의 이동/결합/분리를 고려한 시스템을 개발할 경우, 보안 측면에서 ARP Spoofing, SQL Injection, Rogued $\mathrm{AP}$, Eavesdropping등의 요소가 우선적으로 고려되어 야 함을 볼 수 있다. 또한 Redirection Attack, Frame Injection, Service Request Flooding, Parameter Variation, Malicious Code Dissemination 등도 개발 시 중요하게 고려되어야 하는 요소임을 확인할 수 있다.

\section{$\mathrm{V}$. 보안 요구사항을 고려한 $\mathrm{N}-$ 스크린 협업서비스 프레임워크 구현}

$\mathrm{V}$ 장에서는 $\mathrm{N}$ 스크린 환경에서 웹콘텐츠의 이동을 통 하여 사용자의 개인 정보가 공공 디바이스를 통해 외부 로 공개되는 것을 방지할 수 있는 방안이 적용된 $\mathrm{N}$ 스크 린 협업서비스 프레임워크에 대해서 알아본다. 지금까
지의 HTML 표준 기반 웹 콘텐츠 렌더링(Web Content Rendering)은 단일 페이지에서의 렌더링 상황을 기준으 로 설계되어 있어 단일 콘텐츠 서비스 분리에는 적합하 지 않다. 따라서, 본 연구에서는 웹 콘텐츠를 랜더링하 고 있는 소스 스크린에서 다른 가능한 네트워크 단말간 영상을 스크린 영역 내의 일정 부분에 랜더링하고 입력 이벤트를 전달할 수 있는 방법인 HTML 스트리밍 기술 기반으로 보안 요구사항을 고려한 $\mathrm{N}$ 스크린 협업서비 스 프레임워크를 개발하였다. 또한, 단일 웹페이지에서 일정 영역을 분리 가능하게 만드는 웹 조각화(Web Fragmentation) 기술도 함께 적용하였다.

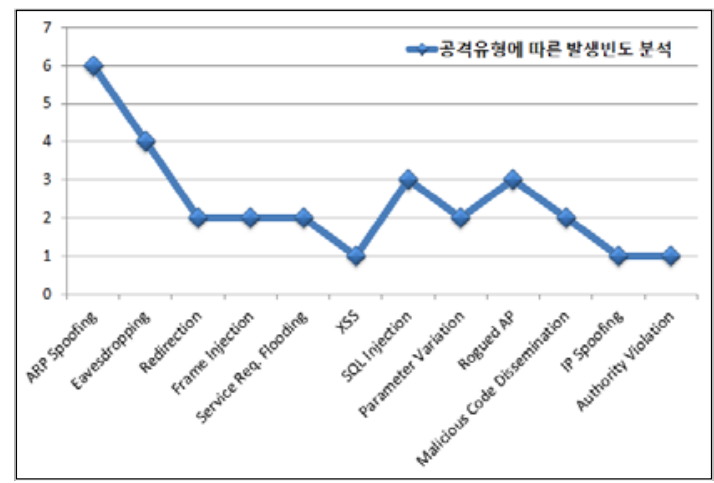

그림 2. 공격유형에 따른 발생빈도 예측 분석

Fig. 2 Occurrence Analysis of Attack Type

그림 3은 $\mathrm{N}$ 스크린 협업서비스 프레임워크의 구조도 이다. 단말에서의 웹 렌더링 결과는 크게 디바이스를 통해 직접적으로 출력되는 부분과 웹 스트림 매니저 (Web Stream Manager)를 통해 다른 디바이스로부터 중 계되어 렌더링되는 부분으로 나뉜다. 이 때, 출처가 다 른 디바이스간의 렌더링 결과는 스크린 관리자(Screen Manager)에 의해 관리된다. 분리된 웹 컴포넌트간 입출 력 교환은 입출력 관리자(Input/Output Manager) 모듈 을 통해 이루어진다. 교환되는 정보의 타입은 크게 입 출력 정보와 자바스크립트(JavaScript) 정보로 나뉜다. 구현된 $\mathrm{N}$ 스크린 협업서비스 프레임워크은 크게 이종 단말 간 HTML 스트리밍 기능과 사용자 입력 기반 웹 조각화 기능을 가지고 있다. 이종 단말 간 HTML 스트 리밍 기능은 단말에서 랜더링 되고 있는 웹 페이지 정 보에 대한 스트리밍 (웹페이지의 부분적 영역의 이미지 Stream 전송)을 통해 웹 부분 이동을 지원하고 입출력 


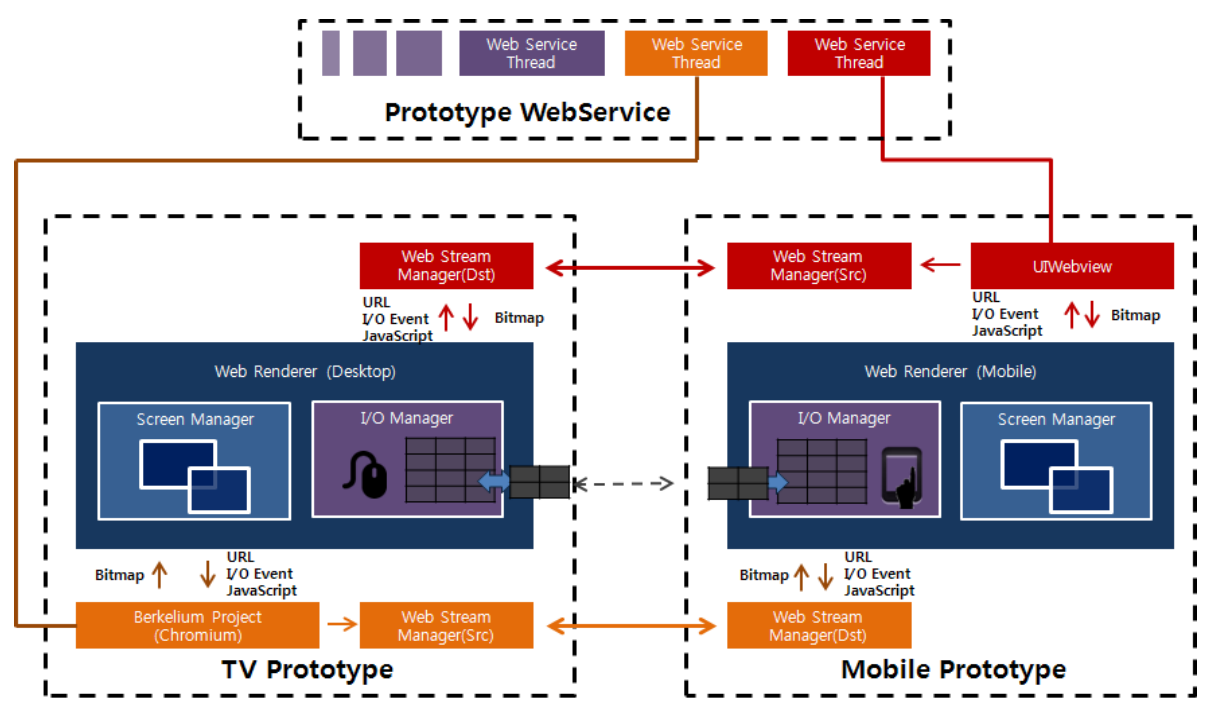

그림 3. 보안 요구사항을 고려한 $\mathrm{N}$ 스크린 협업서비스 프레임워크 구조도

Fig. 3 Architecture of $\mathrm{N}$-screen Cooperation Service Framework Considering Security

정보를 연동을 지원하는 것이다. 사용자 입력기반 웹 조각화 기능은 사용자의 입력정보 (분할하고자 하는 웹 페이지의 특정 부분을 지정하는 터치스크린 입력 등)를 기반으로 연결 대상 디바이스에서 렌더링 되고 있는 웹 페이지에 대한 동적인 영역 분할 및 이동을 지원하는 것이다. 입출력을 연계하는 과정에서 대형 스크린을 가 지고 있는 PC에 개인의 정보가 공개되는 것을 방지하 기 위해서 우리는 아래와 같이 User Interface 보안 방안 을 적용하였다.

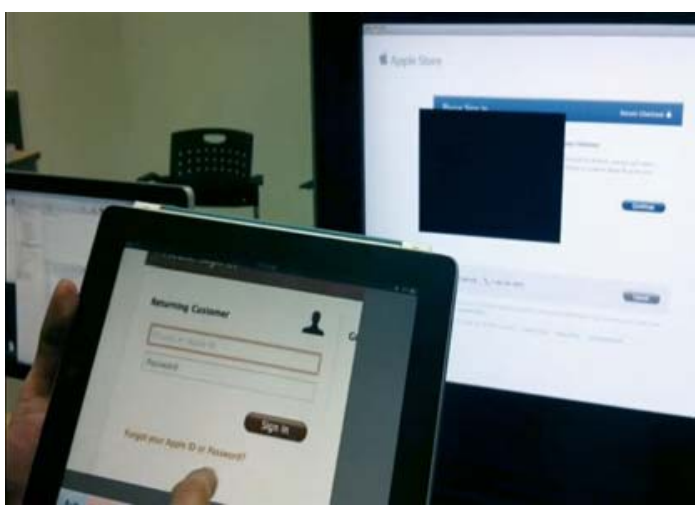

그림 4. N스크린 협업서비스 프레임워크 시연

Fig. $4 \mathrm{~N}$-screen Cooperation Service Framework Demo
TV의 보안 관련 영역이 해당영역을 선택하는 순간 스마트 디바이스로 이동하여 다른 사람들에게 개인의 정보가 공개되는 것을 방지할 수 있다. 그림 3에서는 ID 와 Password를 입력하는 부분이 TV에서 스마트 디바이 스로 이동해 있는 것을 볼 수 있다. 이와 같이, HTML 스트리밍을 기반으로 하는 웹콘텐츠의 이동기술과 보 안 기술이 융합되어 사용자의 정보가 공공 디바이스를 통해서 방지되는 것을 막을 수 있다.

\section{VI. 결 론}

본 논문에서는 다양한 $\mathrm{N}$-스크린서비스 시나리오들 에 대하여 콘텐츠 이동/결합/분리를 고려한 웹보안 기 술 요구사항에 대하여 분석하고 제안하였다. 웹콘텐츠 이동/결합/분리를 고려한 미래의 $\mathrm{N}$ 스크린 서비스 시나 리오를 미리 살펴보고, 이를 위한 보안 위협 상황을 종 합적으로 분석하여, 보안 기술이 개발될 때 고려해야 할 사항들을 미리 살펴보았다. 또한, 웹콘텐츠 이동기 술과 보안기술의 결합을 통해 사용자의 개인정보를 효 과적으로 보호할 수 있다는 것도 확인할 수 있었다.

이동형 웹 컴포넌트는 상호간의 소통이 필수적이며, 단말 간의 경계가 불분명하고 투명하다. 따라서, 기밀 
성(Confidentiality), 무결성(Integrity), 가용성(Availability) 보장으로 대표되는 서비스 보안을 필수적으로 지키고, 웹 콤포넌트 간의 이동/결합/분리의 허용으로 얻 어지는 사용자 경험은 극대화 하되, 고객의 보안 안정성 도 함께 고려하는 방향으로 기술이 개발되어야 한다.

\section{REFERENCES}

[1] Ho-Won Lee, Soo-Bin Lee, "Research on N-Screen Cooperative Service Scenarios and Framework Considering Dynamic Reconfiguration of Web Contents", Global e-Business Association e-Business Study, Vol. 13, No. 3, pp. 461-480, Sep. 2012.

[ 2 ] H. R. Mun, S. H. Kim, and B. H. Chung, "Analysis on Trends for Contents Sharing Technology", ETRI Electronics and Telecommunications Trends, Vol. 25, No 4, Aug. 2010.

[ 3 ] Kim, J., D. Lee, B. C. Jung, and J. Ahn, "Ontology based information distribution in the pervasive display environment",
IEEE PERCOM'2010 Workshops, pp.171- 175, 2010.

[ 4 ] Kim, J., U. Farman, S. Lee, S. Jo, H. Lee, and W. Ryu, "Dynamic addition and deletion of devices in N-screen environment", ICUFN, pp. 118-122, 2012.

[ 5 ] Yoon, C., T. Um, and H. Lee, "Classification of N-Screen Services and its standardization", ICACT, pp. 597-602, 2012.

[6] J. G. Choi, B. N. Noh, "Security Technology Research in Cloud Computing Environment", Journal of Security Engineering, Vol. 8, No. 3, Jun. 2011.

[ 7] J. S. Park, E. K, Cho, and S. G. Kang, "Security Technology for World Wide Web", ETRI Electronics and Telecommunications Trends, Vol. 11 No. 4, Dec. 1996.

[ 8 ] G. B. Cho, "A Survey of Information Security Technology in the Ubiquitous Environments", Samsung SDS Consulting Review, No. 3, 2005.

[9] Michael, C., Developer's Guide To Web Application Security, Syngress, 2007.

[10] Shreeraj, S., Web 2.0 Security: Defending Ajax, RIA, and SOA, Thomson, 2007.

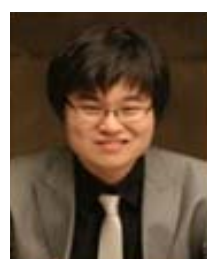

이호원(Howon Lee)

2009년 전기및전자공학과 박사

2009년 2010년 KAIST IT융합연구소 선임연구원

2010년 2012년 KAIST IT융합연구소 팀장/연구조교수

2012년 현재 국립한경대학교 전기전자제어공학과 조교수

2012년 현재 KAIST IT융합연구소 겸직교수

※관심분야 : 차세대 이동통신 시스템, D2D 통신, 최적 CSMA, 지식융합기술 등 